\title{
Educational video improves bowel preparation in patients undergoing colonoscopy: a systematic review and meta-analysis
}

\author{
Ziqi Ye $^{1 \#}$, Jie Chen $^{2 \#}$, Zixue Xuan $^{3}$, Ming Gao $^{1}$, Hongyu Yang $^{1}$ \\ ${ }^{1}$ Department of Pharmacology, The First Affiliated Hospital, College of Medicine, Zhejiang University, Hangzhou 310003, China; ${ }^{2}$ Department of \\ Pharmacy, The Second Affiliated Hospital, College of Medicine, Zhejiang University, Hangzhou 310009, China; ${ }^{3}$ Department of Pharmacy, Zhejiang \\ Provincial People's Hospital, Hangzhou 310014, China \\ Contributions: (I) Conception and design: Z Ye, J Chen; (II) Administrative support: H Yang; (III) Provision of study materials or patients: Z Ye, J \\ Chen; (IV) Collection and assembly of data: Z Ye, J Chen; (V) Data analysis and interpretation: Z Xuan, M Gao; (VI) Manuscript writing: All authors; \\ (VII) Final approval of manuscript: All authors. \\ "These authors contributed equally to this work. \\ Correspondence to: Hongyu Yang. Department of Pharmacology, the First Affiliated Hospital, College of Medicine, Zhejiang University, 79 Qingchun \\ Road, Hangzhou 310003, China. Email: hongyuyang@zju.edu.cn.
}

\begin{abstract}
Background: Unsatisfactory bowel preparation has been reported in 1/3 of colonoscopy cases, with lack of good bowel preparation knowledge being one of the major causes. Although still unclear, educational video is thought to be a good method of improving bowel preparation.

Methods: A systematic review of eight randomized controlled trials (RCTs) comparing the educational video to control group among 1,977 patients was conducted. PubMed, Embase, Clinical Trials.gov, Cochrane Library, and reference lists were searched for relevant reported studies from inception until June 2019. Outcomes of interest included adequate bowel preparation, Ottawa scores, polyp detection, withdraw time, pain scores, and the anxiety state of patients. Besides random events meta-analyses, we also performed a sensitivity analysis to examine whether the results of the meta-analysis were robust.

Results: Compared with the conventional group, the educational video group had significantly higher incidence of adequate bowel preparation [overall risk ratio $(\mathrm{RR})=1.20,95 \% \mathrm{CI}: 1.14,1.25, \mathrm{P}<0.001$ ], lower total Ottawa scores [overall standard mean difference $(\mathrm{SMD})=-0.66,95 \% \mathrm{CI}:-0.91,-0.42, \mathrm{P}<0.001$ ]. However, there was no statistical difference in polyp detection, and withdraw time between the educational video and conventional groups $(\mathrm{P}>0.05)$. In addition, there were no sufficient $\mathrm{RCTs}$ to compare the pain scores and anxiety state of patients between the two groups through meta-analysis.
\end{abstract}

Conclusions: Our findings have demonstrated that educational video can improve bowel preparation in patients undergoing colonoscopy.

Keywords: Educational video; adequate bowel preparation; total Ottawa scores; colonoscopy; meta-analysis

Submitted Aug 05, 2019. Accepted for publication Feb 14, 2020.

doi: 10.21037/apm.2020.03.33

View this article at: http://dx.doi.org/10.21037/apm.2020.03.33

\section{Introduction}

Although the incidence and mortality rate of colorectal cancer (CRC) have decreased these years (1), there remain $4.4 \%$ of $4,619,844$ adults diagnosed with CRC between 2000 to 2014 and it remains the third most common cause of cancer-related deaths in the USA (2). Screening can reduce the mortality rate of CRC, and colonoscopy, which is considered as the standard screening test for CRC, requires adequate bowel preparation (3). Besides prolonging the duration of colonoscopy procedure, inadequate bowel preparation has been shown to incur higher costs due to re-examination $(4,5)$ and reduce polyp detection rates up to $50 \%(6)$. In addition, compared with inadequate bowel 
preparation, a meta-analysis has revealed that high and intermediate quality bowel preparation could increase the adenoma detection rate by $5 \%$ in colonoscopy (7). Further, patients' failure to understand the complex procedural requirements could be a major contributor to the inadequate bowel preparation (8). In a separate study, about $18 \%$ of patients with inadequate bowel preparation did not follow the instructions on dietary restriction and duration of preparation (9). Therefore, instructional leaflets, visual aids (10), educational booklets (11), educational videos (12), and discussions with a health care provider (13), have been utilized to bridge the patients' lack of understanding of the bowel preparation procedures.

Out of these strategies, use of educational video in improving the quality of bowel preparation is preferred since it is acceptable to most patients, including the illiterate (14). However, mixed results have been reported regarding the beneficial impact of educational video on colonoscopy, with some studies affirming its benefits while others showing no significant difference with other conventional education methods. Thus far, there is no meta-analysis comparing the efficiency of the educational video to conventional education in patients undergoing colonoscopy. Therefore, in this study, we performed a systematic review and metaanalysis to assess the suitability of educational video on patients undergoing colonoscopy.

\section{Methods}

\section{Search strategy}

Clinical trials that had been published up to June 2019 were used for this study, and were obtained after a comprehensive literature search on Embase, PubMed, the Clinicaltrials. gov (http://clinicaltrials.gov/), and the Cochrane Library databases. The search terms included "educational video", "video", "colonoscopy", "education", and "colorectal cancer", and only studies that compared the educational video and conventional education methods were selected for this work. Further, we screened the reference lists of review articles and retrieved additional studies from relevant journals through manual search. We exclusively included studies which were published in English.

\section{Inclusion and exclusion criteria}

Studies were selected according to the Preferred Reporting
Items for Systematic Reviews and Meta-Analyses (PRISMA) statement (15). Clinical trials that met the following criteria were included:

(I) Randomized phase II, III, and IV trials;

(II) Patients underwent colonoscopy;

(III) Participants who received the educational video compared to conventional education;

(IV) Availability of information such as sample sizes, events and event rates.

Exclusion criteria included: (I) animal research; (II) reviews; (III) studies with abstracts only; (IV) overlapping data; (V) studies without standard mean difference (SMD), risk ratio $(\mathrm{RR})$, odds ratio $(\mathrm{OR})$ or hazard ratio $(\mathrm{HR})$ with $95 \%$ confidence intervals $(\mathrm{CI})$.

\section{Data extraction and quality assessment}

Literature screening, data extraction, and quality assessment of the studies were independently conducted by two reviewers. However, upon disagreements between them, a third reviewer adjudicated until consensus was reached. The extracted information from each article included first author's name, year of publication, trials type, country, the number of patients, patients' age, body mass index (BMI), previous experience of colonoscopy, and the outcomes. Moreover, the quality of the methodology in randomized controlled trials (RCTs) was assessed using the Jadad criteria (16), and the quality of each trial was graded as either high-quality (score $\geq 3$ ) or low-quality trials (score $\leq 2$ ).

\section{Statistical analysis}

Data of patients with outcomes were extracted from all of the included trials. SMD, RR and 95\% CI were then calculated to assess the association between each regimen and its respective outcome. Further, the Q statistic and $\mathrm{I}^{2}$ statistic were used to assess the heterogeneity, with $\mathrm{I}^{2}>50 \%$ signifying statistical significance. The random-effect model was also used in the meta-analyses for conservative statistics, and besides Begg adjusted rank correlation test and Egger regression tests, a funnel plot used for assessing the publication bias $(17,18)$. In addition, to determine the robustness of the meta-analysis results, we performed a sensitivity analysis test. Statistical significance was set at $\mathrm{P}<0.05$, and STATA statistical version 12.0 was used to perform all the statistical analyses (Stata Corporation, College Station, Texas, USA). All P values were two-sided. 


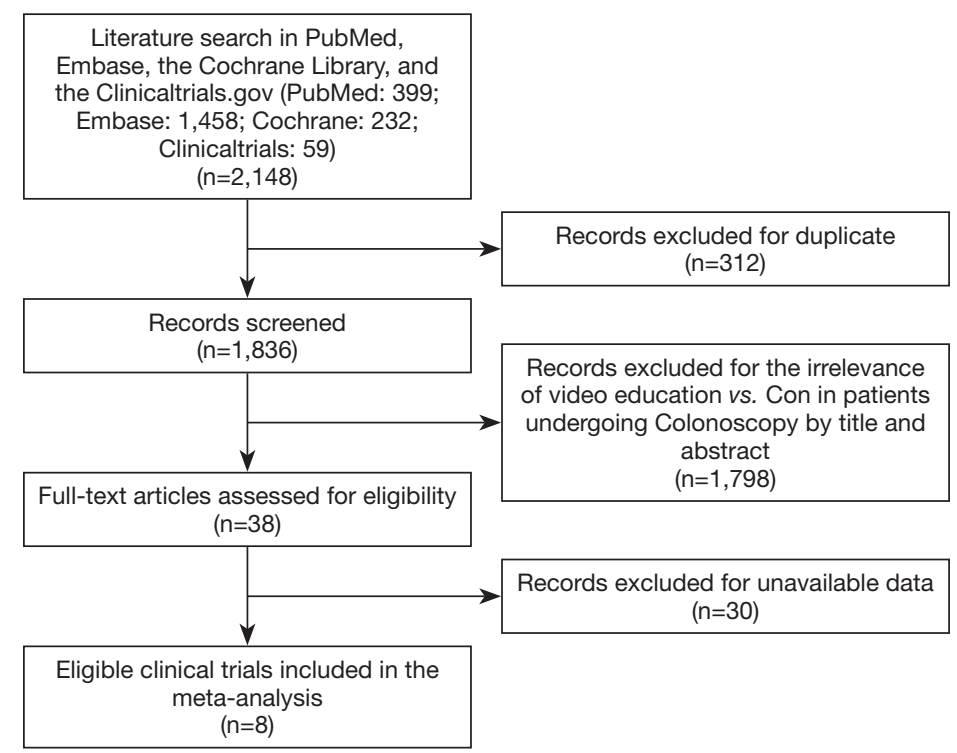

Figure 1 Flow chart representing eligible studies. Con, conventional group.

\section{Results}

\section{Characteristics of studies included in this study}

Our search yielded a total of 2,148 potentially relevant clinical trials that used either educational video or conventional education methods on patients who underwent colonoscopy. After further review and screening, eight RCTs comprising of 1,977 subjects met the inclusion criteria $(6,19-25)$ and were pooled for the meta-analyses (Figure 1). The baseline characteristics of each trial are shown in Table 1. All trials included were single-blinded and the number of enrolled patients ranged from 92 to 502 for each trial. In addition, the quality of the included RCTs (Jadad scores) ranged between 2 and 3. According to the eligibility criteria of the majority of the trials, patients with impaired hepatic, renal or bone marrow function were excluded and most of the patients had Eastern Cooperative Oncology Group (ECOG) performance-status scores of 0 or 1 . In this systematic review, we followed the guidelines of the PRISMA statement.

\section{Findings—adequate bowel preparation}

A total of 1,588 subjects who received the educational video training or conventional education in six trials were used for the analysis of adequate bowel preparation (data shown in Table 2). Data from the adequate bowel preparation between the educational video and conventional education arms revealed a summary RR of 1.20 (95\% CI: 1.14, 1.25, $\mathrm{I}^{2}=0 \%$ ) (Figure 2). We observed that the educational video group had a higher incidence of adequate bowel preparation compared with the conventional education group $(\mathrm{P}<0.001)$.

Subsequently, a total of 1,496 subjects who received the educational video training or conventional education in five trials were used for the analysis of total Ottawa Bowel Preparation Quality Scores, ranging from 0 (perfect) to 14 (inadequate) (data shown in Table 2). These scores are commonly known as Ottawa scores and represent the quality of bowel preparation. The total Ottawa scores between the educational video and conventional education groups revealed a summary SMD of -0.66 (95\% CI: -0.91 , $-0.42, \mathrm{I}^{2}=79.6 \%$ ) (Figure 3). The results showed that the educational video group had lower total Ottawa scores compared with the conventional education group $(\mathrm{P}<0.001)$.

Although the outcomes-based total Ottawa scores indicated statistically significant heterogeneity, the sensitivity analysis showed that the results of total Ottawa score outcomes were robust (Figure S1).

\section{Findings—polyp detection}

A total of 1,259 subjects who received the educational video training or conventional education in three trials were used for the polyp detection analysis (data shown in Table 2). Polyp detection results between the educational video and conventional education groups revealed a summary 
Table 1 Characteristics of all studies

\begin{tabular}{|c|c|c|c|c|c|c|c|c|}
\hline Study & Country & $\begin{array}{l}\text { Trials } \\
\text { type }\end{array}$ & $\begin{array}{c}\text { Number } \\
\text { (video/Con) }\end{array}$ & $\begin{array}{l}\text { Age (years) } \\
\text { (video/Con) }\end{array}$ & $\begin{array}{l}\text { BMI }\left(\mathrm{kg} / \mathrm{m}^{2}\right) \\
\text { (video/Con) }\end{array}$ & $\begin{array}{l}\text { Previous experience } \\
\text { of colonoscopy }(\mathrm{N})\end{array}$ & Outcomes & $\begin{array}{l}\text { Jadad } \\
\text { score }\end{array}$ \\
\hline $\begin{array}{l}\text { Jeon } \\
2019(19)\end{array}$ & Korea & $\mathrm{RCT}$ & $140 / 141$ & $46.7 / 49.9$ & $23.5 / 24.5$ & $73 / 83$ & $\begin{array}{l}\text { BP, Ottawa scores, colonoscopy } \\
\text { outcomes, side effects }\end{array}$ & 2 \\
\hline $\begin{array}{l}\text { Pillai } \\
2018(20)\end{array}$ & USA & $\mathrm{RCT}$ & $56 / 48$ & - & - & - & $\begin{array}{l}\text { Ottawa scores, inadequate BP, } \\
\text { knowledge score }\end{array}$ & 3 \\
\hline $\begin{array}{l}\text { Rice } \\
2016(22)\end{array}$ & USA & $\mathrm{RCT}$ & $42 / 50$ & $60.1 / 61.0$ & $32.8 / 30.9$ & $23 / 24$ & Boston bowel preparation scores & 3 \\
\hline $\begin{array}{l}\text { Park } \\
2016(23)\end{array}$ & Korea & $\mathrm{RCT}$ & $250 / 252$ & $49.2 / 47.3$ & $24.3 / 24.7$ & $154 / 143$ & $\begin{array}{l}\text { Ottawa scores, procedure time, } \\
\text { polyp detection rate }\end{array}$ & 2 \\
\hline $\begin{array}{l}\text { Bytzer } \\
2007 \text { (25) }\end{array}$ & Danmark & RCT & $72 / 90$ & $52.8 / 53.4$ & - & $9 / 14$ & $\begin{array}{l}\text { Pain scores, STAI-S scores, } \\
\text { procedure time, colonic cleansing }\end{array}$ & 3 \\
\hline
\end{tabular}

RCT, randomized controlled trial; Con, conventional group; N, number of patients; BP, bowel preparation; Ottawa scores, Ottawa Bowel Preparation Quality Scores.

Table 2 Data of outcomes

\begin{tabular}{|c|c|c|c|c|c|c|c|c|c|c|c|c|}
\hline \multirow[t]{2}{*}{ Study } & \multicolumn{2}{|c|}{$\begin{array}{l}\text { Adequate bowel } \\
\text { preparation }(\mathrm{N})\end{array}$} & \multicolumn{2}{|c|}{$\begin{array}{c}\text { Polyp } \\
\text { detection (N) }\end{array}$} & \multicolumn{2}{|c|}{$\begin{array}{l}\text { Withdraw } \\
\text { time (min) }\end{array}$} & \multicolumn{2}{|c|}{ Total Ottawa scores } & \multicolumn{2}{|c|}{ Pain scores } & \multicolumn{2}{|c|}{ STAI-S scores } \\
\hline & Video & Con & Video & Con & Video & Con & Video & Con & Video & Con & Video & Con \\
\hline Pillai 2018 & 51 & 37 & - & - & - & - & $4.77 \pm 4.0$ & $6.85 \pm 4.00$ & - & - & - & - \\
\hline Park 2016 & 229 & 198 & 34 & 34 & $6.6 \pm 2.7$ & $6.9 \pm 3.9$ & $3.03 \pm 1.90$ & $4.21 \pm 1.90$ & - & - & - & - \\
\hline $\begin{array}{l}\text { Prakash } \\
2013\end{array}$ & 67 & 48 & - & - & - & - & $4.0 \pm 0.8$ & $5.0 \pm 1.0$ & - & - & - & - \\
\hline Arabul 2012 & - & - & - & - & - & - & - & - & $2.58 \pm 0.73$ & $2.99 \pm 0.51$ & $40.5 \pm 10.4$ & $45.0 \pm 8.9$ \\
\hline
\end{tabular}

Ottawa scores, Ottawa Bowel Preparation Quality Scores; Con, conventional group; STAI-S scores, Spielberger State-Trait Anxiety Inventory-State Scores; N, number of patients; min, minutes. 
Study

ID
P value of RR RR $(95 \% \mathrm{Cl})$

Weight

\begin{tabular}{|c|c|c|c|}
\hline Jeon (2019) & & $1.19(0.93,1.53)$ & 3.69 \\
\hline Pillai (2018) & - & $1.18(0.99,1.41)$ & 7.67 \\
\hline Liu (2018) & & $1.20(1.10,1.30)$ & 32.67 \\
\hline Rice (2016) & & $1.09(0.84,1.41)$ & 3.41 \\
\hline Park (2016) & & $1.17(1.08,1.26)$ & 42.06 \\
\hline Prakash (2013) & $\rightarrow-$ & $1.37(1.18,1.59)$ & 10.50 \\
\hline Overall (I-squared $=0.0 \%, p=0.518$ ) & $<0.001$ & $1.20(1.14,1.25)$ & 100.00 \\
\hline NOTE: Weights are from random effects analysis & & & \\
\hline $\begin{array}{c}.628 \\
\text { Favors conventional group }\end{array}$ & & $\begin{array}{l}9 \\
\text { ideo group }\end{array}$ & \\
\hline
\end{tabular}

Figure 2 Annotated forest plot for meta-analysis of adequate bowel preparation outcomes of the educational video and conventional groups. Summary of adequate bowel preparation outcomes (RR) between the educational video and conventional groups were calculated using the random effect model. Size of squares is directly proportional to the amount of information available. RR, risk ratio; P, P value of the Q test for heterogeneity.

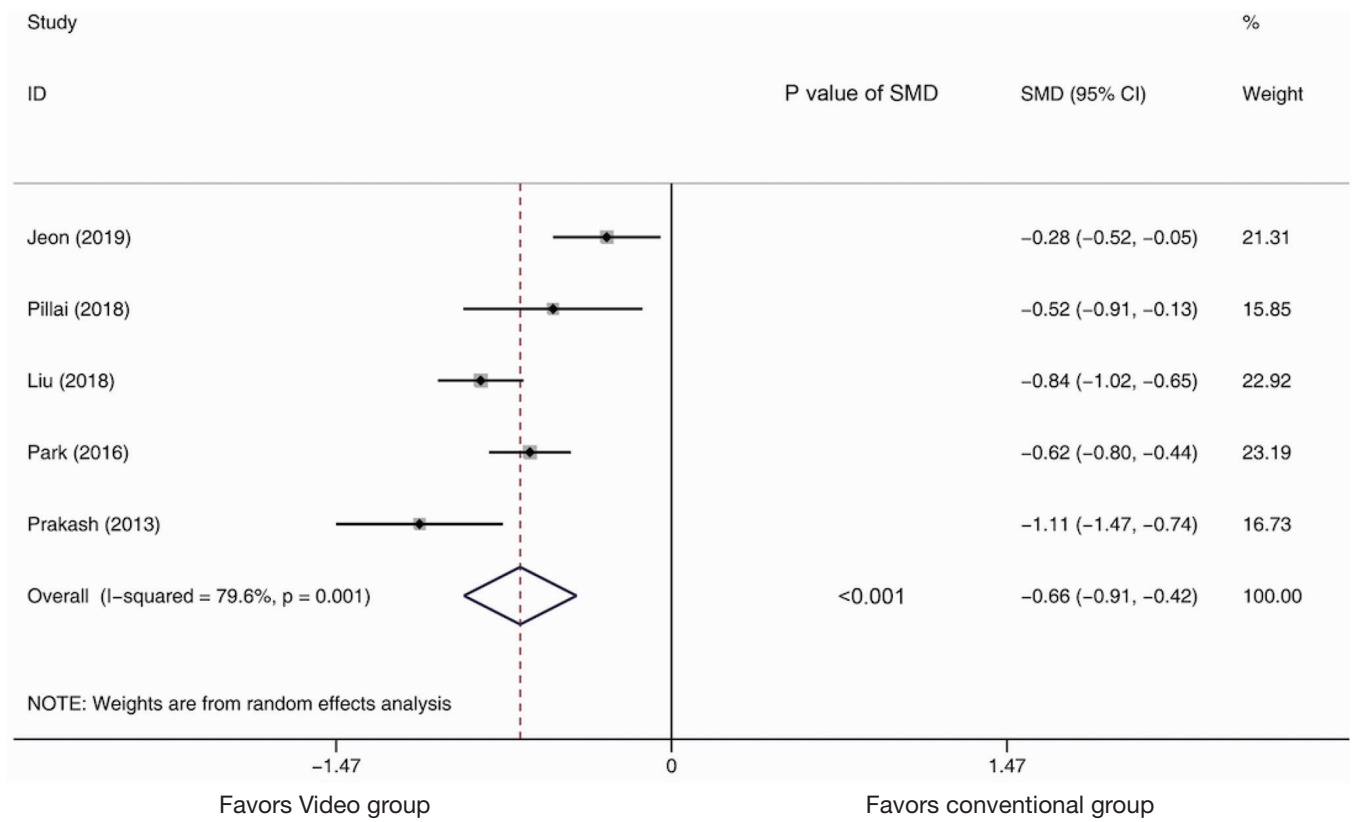

Figure 3 Annotated forest plot for meta-analysis of total Ottawa scores outcomes of the educational video and conventional groups. Summary of total Ottawa scores outcomes (SMD) between the educational video and conventional groups were calculated using the random effect model. Size of squares is directly proportional to the amount of information available. SMD, standard mean difference; $\mathrm{P}$, P value of the $\mathrm{Q}$ test for heterogeneity. 


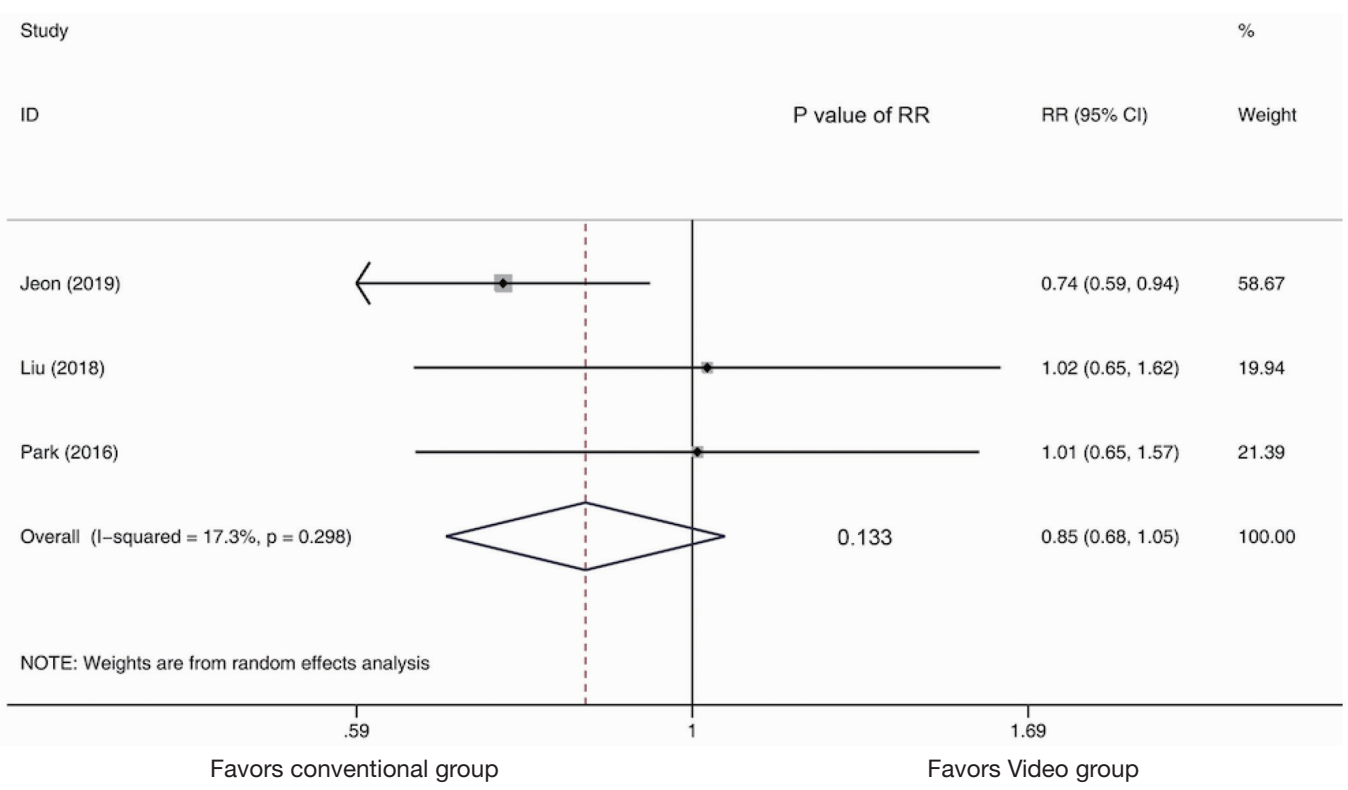

Figure 4 Annotated forest plot for meta-analysis of polyp detection outcomes of the educational video and conventional groups. Summary of polyp detection outcomes (RR) between the educational video and conventional groups were calculated using the random effect model. Size of squares is directly proportional to the amount of information available. RR, risk ratio; P, P value of the Q test for heterogeneity.

RR of 0.85 (95\% CI: $0.68,1.05, \mathrm{I}^{2}=17.3 \%$ ) (Figure 4), and exhibited no statistical difference in polyp detection between the two groups $(\mathrm{P}=0.133)$.

\section{Findings-Withdraw time}

In the meta-analysis, patients from three studies were included for analysis of withdraw time (data shown in Table 2). As shown in Figure 5, the withdraw time between the educational video and conventional education arms revealed a summary SMD of -0.14 (95\% CI: $-0.27,-0.00$, $\left.\mathrm{I}^{2}=31.4 \%\right)$. Although the $\mathrm{P}$ value of SMD was 0.046 , the results showed no statistical difference in withdraw time between the educational video and conventional education groups since the upper limit of $95 \%$ CI was -0.00 .

\section{Publication bias}

There was no significant publication bias $(\mathrm{P}=0.803$ for the Egger's test; $\mathrm{P}=1.000$ for the Begg's test) revealed in this study (Figure S2). Furthermore, the funnel plot's shape did not display any evidence of asymmetry.

\section{Discussion}

Globally, CRC ranks second and third among the most commonly diagnosed cancers in females and males, respectively. However, CRC screening can reduce the mortality of CRC, with colonoscopy considered as the golden standard test for screening CRC (3). Adequate bowel preparation is necessary for enhancing clear observation of the mucosal surface during the colonoscopy procedure. Besides, studies have shown that inadequate bowel preparation occurs in up to $25 \%$ of colonoscopy procedures $(4,26)$. The conventional issuance of instructional leaflets to patients to improve the quality of bowel preparation has yielded unsatisfactory results. Therefore, the alternative use of educational video has been proposed by other studies to be a highly attractive strategy because it is acceptable to most of the patients, including the illiterate ones (14). Mixed results have been reported from different studies regarding the beneficial impact of educational video on colonoscopy, with some studies affirming its benefits while others showing no significant difference with other conventional education methods. Thus far, the results from clinical 


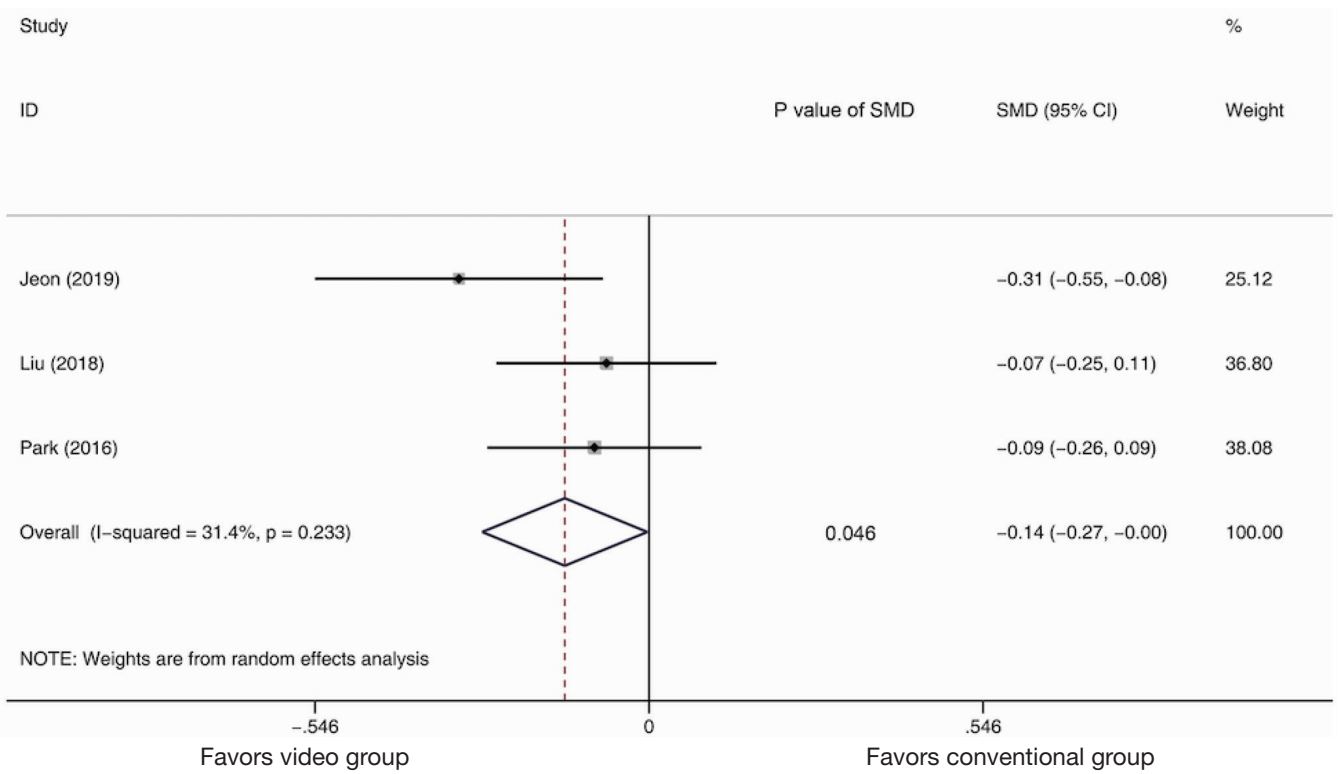

Figure 5 Annotated forest plot for meta-analysis of withdraw time outcomes of the educational video and conventional groups. Summary of withdraw time outcomes (SMD) between the educational video and conventional groups were calculated using the random effect model. Size of squares is directly proportional to the amount of information available. SMD, standard mean difference; $\mathrm{P}, \mathrm{P}$ value of the $\mathrm{Q}$ test for heterogeneity.

trials are not compelling enough to draw any definitive conclusions about the superiority of the educational video in colonoscopy. Herein, we performed a systematic review and meta-analysis on the efficacy of the educational video and conventional care for patients undergoing colonoscopy. The study was based on eight RCTs which comprised of 1,977 patients. From the results, we observed that: (I) The educational video group had significantly higher incidence of adequate bowel preparation, and lower total Ottawa scores than the conventional group. (II) There was no statistical difference in polyp detection and withdraw time between the educational video and conventional groups.

Adenoma and polyp detection rates are important criteria for evaluating the quality of colonoscopy. In this study however, only one included RCT assessed the adenoma detection rate, and the results revealed that the educational video group had significant lower adenoma detection rate than control group $(\mathrm{P}=0.028)$ (19). Conversely, a cohort study reported lack of significant difference of adenoma detection rate between these two groups $(\mathrm{P}=0.85)$. However, since we did not have enough RCTs that assessed adenoma detection rate between these two groups, we could not draw any definite conclusion. In addition, we also focused on outcome polyp detection rates, of which the pooled meta- analysis results showed lack of statistical difference between the educational video and conventional groups. This is an indication that the educational video did not improve the polyp detection rate when compared to the conventional group.

Proper bowel preparation is a key process that precedes colonoscopy, since besides providing a good view of the entire colonic mucosa, it improves the safety of the whole examination procedures (27). Conversely, improper bowel preparation increases the time of examination and incidences of complications (28). From our pooled metaanalysis results, we observed that the educational video could significantly enhance bowel preparation, which could further improve the quality of colonoscopy. Furthermore, Ottawa score is also an important criterion which represents the quality of bowel preparation, with the scores ranging from 0 (perfect) to 14 (inadequate) (29). The pooled results of meta-analysis revealed that the educational video had significantly lower total Ottawa scores than the control group, which was consistent with the results of proper bowel preparation.

Further, the meta-analysis results also exhibited no statistical difference in withdraw time between the educational video and conventional groups. Since 
colonoscopy entails careful observation of the colonic mucosa, studies have reported that withdraw time of above 6 minutes can significantly increase the adenoma detection rate (30). However, our meta-analysis results showed that the educational video was not associated with withdraw time of colonoscopy. These results were consistent with the previous results of polyp detection rate.

Despite the use of sedation, colonoscopy is not well tolerated by many patients since it is accompanied by pain and anxiety. Spielberger State-Trait Anxiety Inventory-State (STAI-S) score is widely used to assess the state of anxiety. In our review, one RCT concluded that the educational video group had significantly lower pain scores and STAI-S scores than the control group $(\mathrm{P}<0.001$ and $\mathrm{P}=0.001$, respectively) (data list in Table 2) (24). Conversely, another RCT reported that the educational video did not affect the pain and anxiety state of patients undergoing colonoscopy $(\mathrm{P}>0.05)$ (25). However, since we lacked enough trials that assessed pain and STAI-S scores between these two groups, we could not draw any definite conclusion.

Since heterogeneity is an important factor in metaanalysis studies, we performed sensitivity analysis which revealed that no study affected the overall significance of the pooled estimates, hence our findings were robust. Publication bias might introduce false positives in the metaanalysis (18). To avoid the possible bias, the studies included were all properly assessed. To detect publication bias, known for introducing false positives in meta-analysis, Begg's and Egger's tests were used. However, we did not find any evidence of bias. Moreover, these results of publication bias and sensitivity analysis confirmed the credibility of our findings.

This present meta-analysis had its limitations and should therefore be interpreted with caution. First, we used few studies, especially due to the lack of sufficient high-quality RCTs. Second, the educational video protocols used in the included RCTs were inconsistent, hence additional rigorously designed experiments are required. Finally, there were insufficient RCTs to compare the adenoma detection rate, pain scores and STAI-S scores between the educational video and conventional groups.

\section{Conclusions}

In conclusion, compared with the conventional group, we observed that the educational video group had a higher incidence of adequate bowel preparation, lower total Ottawa scores but similar polyp detection rate and withdraw time. These findings consistently showed that the educational video can improve bowel preparation in patients undergoing colonoscopy.

\section{Acknowledgments}

We thank all our collaborators who helped with this study. Funding: This work was supported by Joint Fund of Zhejiang Provincial Natural Science Foundation, China (Grant number LYY18H310002), Funding of Zhejiang Pharmaceutical Association (Grant number ZYYZL01).

\section{Footnote}

Conflicts of interest: All authors have completed the ICMJE uniform disclosure form (available at http://dx.doi. org/10.21037/apm.2020.03.33). The authors have no conflicts of interest to declare.

Ethical Statement: The authors are accountable for aspects of the work in ensuring that questions related to the accuracy or integrity of any part of the work are appropriately investigated and resolved.

Open Access Statement: This is an Open Access article distributed in accordance with the Creative Commons Attribution-NonCommercial-NoDerivs 4.0 International License (CC BY-NC-ND 4.0), which permits the noncommercial replication and distribution of the article with the strict proviso that no changes or edits are made and the original work is properly cited (including links to both the formal publication through the relevant DOI and the license). See: https://creativecommons.org/licenses/by-nc-nd/4.0/.

\section{References}

1. Espey DK, Wu XC, Swan J, et al. Annual report to the nation on the status of cancer, 1975-2004, featuring cancer in American Indians and Alaska Natives. Cancer 2007;110:2119-52.

2. Allemani C, Matsuda T, Di Carlo V, et al. Global surveillance of trends in cancer survival 2000-14 (CONCORD-3): analysis of individual records for 37 513025 patients diagnosed with one of 18 cancers from 322 population-based registries in 71 countries. Lancet 2018;391:1023-75. 
3. Stock D, Paszat LF, Rabeneck L. Colorectal cancer mortality reduction is associated with having at least 1 colonoscopy within the previous 10 years among a population-wide cohort of screening age. Gastrointest Endosc 2016;84:133-41.

4. Harewood GC, Sharma VK, de Garmo P. Impact of colonoscopy preparation quality on detection of suspected colonic neoplasia. Gastrointest Endosc 2003;58:76-9.

5. Rex DK, Imperiale TF, Latinovich DR, et al. Impact of bowel preparation on efficiency and cost of colonoscopy. Am J Gastroenterol 2002;97:1696-700.

6. Prakash SR, Verma S, McGowan J, et al. Improving the quality of colonoscopy bowel preparation using an educational video. Can J Gastroenterol 2013;27:696-700.

7. Clark BT, Rustagi T, Laine L. What level of bowel prep quality requires early repeat colonoscopy: systematic review and meta-analysis of the impact of preparation quality on adenoma detection rate. Am J Gastroenterol 2014;109:1714-23; quiz 1724.

8. Chung YW, Han DS, Park KH, et al. Patient factors predictive of inadequate bowel preparation using polyethylene glycol: a prospective study in Korea. J Clin Gastroenterol 2009;43:448-52.

9. Nguyen DL, Wieland M. Risk factors predictive of poor quality preparation during average risk colonoscopy screening: the importance of health literacy. J Gastrointestin Liver Dis 2010;19:369-72.

10. Calderwood AH, Lai EJ, Fix OK, et al. An endoscopistblinded, randomized, controlled trial of a simple visual aid to improve bowel preparation for screening colonoscopy. Gastrointest Endosc 2011;73:307-14.

11. Spiegel BM, Talley J, Shekelle P, et al. Development and validation of a novel patient educational booklet to enhance colonoscopy preparation. Am J Gastroenterol 2011;106:875-83.

12. Hayat U, Lee PJ, Lopez R, et al. Online Educational Video Improves Bowel Preparation and Reduces the Need for Repeat Colonoscopy Within Three Years. Am J Med 2016;129:1219.e1-1219.e9.

13. Rosenfeld G, Krygier D, Enns RA, et al. The impact of patient education on the quality of inpatient bowel preparation for colonoscopy. Can J Gastroenterol 2010;24:543-6.

14. Zapka JG, Lemon SC, Puleo E, et al. Patient education for colon cancer screening: a randomized trial of a video mailed before a physical examination. Ann Intern Med 2004;141:683-92.

15. Moher D, Liberati A, Tetzlaff J, et al. Preferred reporting items for systematic reviews and meta-analyses: the PRISMA statement. BMJ 2009;339:b2535.

16. Jadad AR, Moore RA, Carroll D, et al. Assessing the quality of reports of randomized clinical trials: is blinding necessary? Control Clin Trials 1996;17:1-12.

17. Begg CB, Mazumdar M. Operating characteristics of a rank correlation test for publication bias. Biometrics 1994;50:1088-101.

18. Egger M, Davey Smith G, Schneider M, et al. Bias in meta-analysis detected by a simple, graphical test. BMJ 1997;315:629-34.

19. Jeon SC, Kim JH, Kim SJ, et al. Effect of Sending Educational Video Clips via Smartphone Mobile Messenger on Bowel Preparation before Colonoscopy. Clin Endosc 2019;52:53-58.

20. Pillai A, Menon R, Oustecky D, et al. Educational Colonoscopy Video Enhances Bowel Preparation Quality and Comprehension in an Inner City Population. J Clin Gastroenterol 2018;52:515-8.

21. Liu C, Song X, Hao H. Educational Video Followed by Retelling Bowel Preparation Process to Improve Colonoscopy Bowel Preparation Quality: A Prospective Nursing Intervention Study. Med Sci Monit 2018;24:6029-37.

22. Rice SC, Higginbotham T, Dean MJ, et al. Video on Diet Before Outpatient Colonoscopy Does Not Improve Quality of Bowel Preparation: A Prospective, Randomized, Controlled Trial. Am J Gastroenterol 2016;111:1564-71.

23. Park JS, Kim MS, Kim H, et al. A randomized controlled trial of an educational video to improve quality of bowel preparation for colonoscopy. BMC Gastroenterol 2016;16:64.

24. Arabul M, Kandemir A, Celik M, et al. Impact of an information video before colonoscopy on patient satisfaction and anxiety. Turk J Gastroenterol 2012;23:523-9.

25. Bytzer P, Lindeberg B. Impact of an information video before colonoscopy on patient satisfaction and anxiety - a randomized trial. Endoscopy 2007;39:710-4.

26. Froehlich F, Wietlisbach V, Gonvers JJ, et al. Impact of colonic cleansing on quality and diagnostic yield of colonoscopy: the European Panel of Appropriateness of Gastrointestinal Endoscopy European multicenter study. Gastrointest Endosc 2005;61:378-84.

27. Landreneau SW, Di Palma JA. Update on preparation for colonoscopy. Curr Gastroenterol Rep 2010;12:366-73.

28. Chokshi RV, Hovis CE, Hollander T, et al. Prevalence of missed adenomas in patients with inadequate bowel 
preparation on screening colonoscopy. Gastrointest Endosc 2012;75:1197-203.

29. Rostom A, Jolicoeur E. Validation of a new scale for the assessment of bowel preparation quality. Gastrointest

Cite this article as: Ye Z, Chen J, Xuan Z, Gao M, Yang H. Educational video improves bowel preparation in patients undergoing colonoscopy: a systematic review and meta-analysis. Ann Palliat Med 2020;9(3):671-680. doi: 10.21037/apm.2020.03.33
Endosc 2004;59:482-6.

30. Rex DK, Petrini JL, Baron TH, et al. Quality indicators for colonoscopy. Gastrointest Endosc 2006;63:S16-28. 


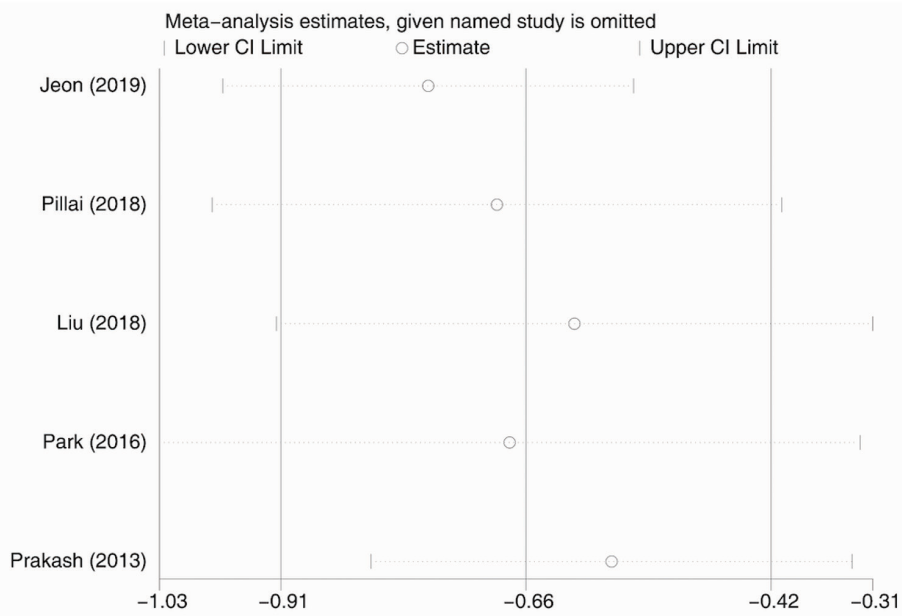

Figure S1 Sensitivity analysis of total Ottawa scores outcomes.

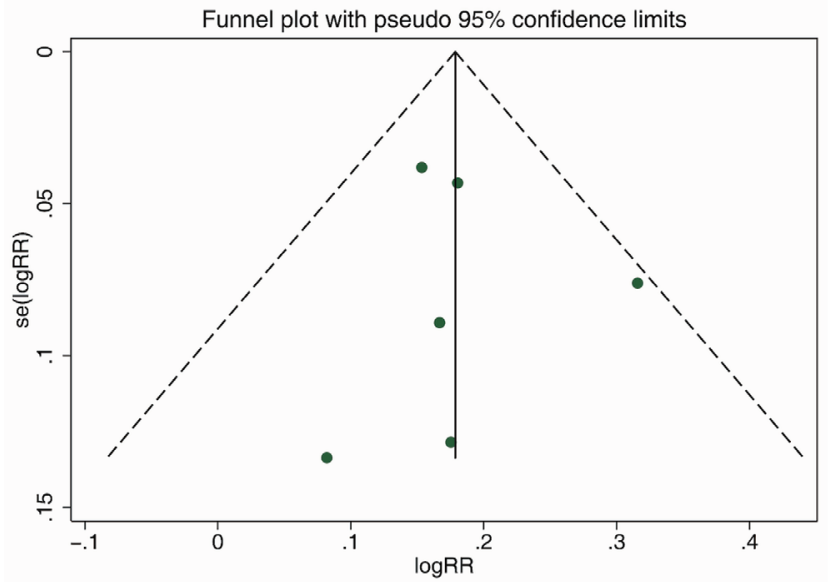

Figure S2 Publication bias risk of adequate bowel preparation outcomes. RR, risk ratio; se, standard error of the mean. 